\title{
El difícil equilibrio entre la globalización de los derechos y su contextualización desde la perspectiva de la doctrina del mar- gen de apreciación nacional
}

\author{
Federico de Montalvo Jääskeläinen \\ Profesor propio adjunto Derecho constitucional \\ Facultad de Derecho, Universidad Pontificia de Comillas (ICADE)
}

Recibido: 01.10.2012

Aceptado: 15.10.2012

\begin{abstract}
Resumen: Uno de los principales debates que ha generado el fenómeno de la universalización de los derechos fundamentales tanto en el Derecho constitucional como en la propia Teoría General del Derecho es el del necesario equilibrio entre dicho fenómeno y la aplicación contextualizada de los derechos en un marco político, social y cultural concreto. Al amparo de este debate surge, en sede del Tribunal Europeo de Derechos Humanos, la doctrina del margen de apreciación nacional, como instrumento que pretende equilibrar los principios de integración y subsidiariedad que presiden el CEDH. Dicha doctrina, más allá de su virtualidad o necesidad, carece aún hoy de una construcción precisa y sistematizada que permita a los actores que han de intervenir ante dicho Tribunal, Estados miembros y ciudadanos, poder prever con la suficiente seguridad jurídica el uso que de la misma se hace ¿Significa dicha falta de sistematización que hubiera de optarse por prescindir de la doctrina del margen de apreciación nacional?
\end{abstract}

Palabras clave: Convenio Europeo de Derechos Humanos, Tribunal Europeo de Derechos Humanos, contextualización de los derechos humanos, universalización de los derechos fundamentales, principio de integración, margen de apreciación nacional.

Abstract: One of the main debates provoked by the phenomenon of the universalization of human rights is about balance between this phenomenon and the application of human rights in specific political, social and cultural contexts, and is relevant both in the field of Constitutional Law as well as in the field of Legal Theory. The doctrine of the national margin of appreciation, created by the European Court of Human Rights, has arisen as a response to this debate. This doctrine can be considered a real instrument attempting to balance the two principles of integration and subsidiarity of the European Convention on Human Rights. Currently, this legal doctrine lacks a systematic and complete construction which would allow the main actors of the European system of Human Rights, Member States and citizens to predict, with enough legal certainty, the use of the doctrine by the Court. Does this mean that it is better to opt not to use the doctrine of national margin of appreciation?

Key words: European Convention on Human Rights, European Court of Human Rights, human rights contextualization, universalization of human rights, integration principle, national margin of appreciation doctrine. 
Sumario: 1. Introducción.-2. Origen y evolución de la doctrina del margen de apreciación nacional.-3. Fundamento y elementos integrantes de la doctrina.-4. La principal crítica a la doctrina: su falta de sistematización.- 5. Contextualización de los derechos en la unión europea: el caso omega.-6. Conclusiones.

\section{INTRODUCCIÓN}

La aprobación en el marco del Consejo de Europa del Convenio Europeo de Derechos Humanos (en adelante, CEDH) y la creación del correspondiente Tribunal Europeo (en adelante, TEDH) prevista en el mismo han supuesto un trascendental avance para la pretensión, reforzada tras la experiencia de la Segunda Guerra Mundial, de integrar los derechos fundamentales y libertades públicas en el Viejo Continente, constituyendo una garantía colectiva de los mismos. Lo mismo puede predicarse de la Carta Europea creada en el marco de la Unión, aunque con los límites que han venido destacando algunos Tribunales de los Estados miembros acerca de su eficacia limitada a las relaciones entre ciudadanos e Instituciones de la Unión ${ }^{1}$.

Esta firme voluntad de europeizar los derechos fundamentales y libertades públicas en un marco territorial superior al nacional podría enmarcarse, como precedente, en lo que se ha denominado globalización o universalización de los derechos. Ciertamente, a primera vista, ello sería un éxito porque es cierto que la experiencia histórica nos ha demostrado que los derechos no pueden quedar circunscritos a la frontera de un Estado, sobre todo, aquellos que conectan, no con la condición de ciudadano político, sino con la condición de ser humano. Además, como destaca el propio Preámbulo del Convenio, uno de los cauces para lograr una mayor convivencia pacífica e, incluso, unión entre los Estados es, precisamente, a través de una protección integrada y colectiva de los derechos y libertades. Sin embargo, tampoco puede desconocerse que una globalización que no atienda en cierto modo al contexto concreto en el que se desarrollan los derechos puede también abocar al fracaso de la eficacia de los derechos y, peor aún, a promover no ya la prevención y resolución de conflictos entre derechos, sino precisamente su aparición. Recuérdese que tanto la inflación de derechos como su aplicación de manera descontextualizada pueden ser provocadoras de conflictos ${ }^{2}$. La universalidad

${ }^{1}$ Vid. en especial, Sentencia de la Sala de lo Contencioso-Administrativo (Pleno) del Tribunal Supremo de 11-II-2009 (caso Educación para la ciudadanía). Por otro lado, no debemos que el Tratado de Lisboa estableció un sistema de integración diferenciado, de manera que dos Estados no han quedado plenamente incorporados a la Carta, Reino Unido y Polonia. Vid. TAJadura Tejada, J., «La desconstitucionalización de los derechos fundamentales en el Tratado de Lisboa: los límites de la integración diferenciada», Comunicación presentada en el VIII Congreso de la Asociación de Constitucionalistas de España, 2010, p. 5.

${ }^{2}$ El propio recelo que el Tribunal Constitucional Federal alemán ha venido mostrando a cualquier injerencia por parte del Tribunal Europeo o del Derecho comunitario en los 
no puede ser confundida con la eternidad y, de este modo, los derechos más allá de su fundamentación más iuspositivista o más iusnaturalista responden a un contexto histórico concreto, sin que ello signifique que el único fundamento de los derechos sea historicista ${ }^{3}$.

La descontextualización de los derechos supone, en definitiva, el principal reto al que debe enfrentarse el fenómeno de la globalización, so pena de poder provocar distorsiones en los sistemas jurídicos nacionales de derechos. Ciertamente, ello no supone que cualquier pretensión globalizadora sea, en definitiva, imposible ni que haya que optar por un mero discurso en materia de derechos localista o etnicista. Sin embargo, el reconocimiento del derecho con carácter de universalidad no supone descontextualizar el contenido o, mejor dicho, la forma de ejercicio del mismo. Los derechos humanos no se pueden ni deben construir en torno a un tiempo y un espacio abstractos, lo cual proporciona a aquéllos una expresión de universalidad abstracta y de vaciedad antropológica, sino que los derechos han de estar inmersos en una temporalidad y en una espacio concreto. Los derechos deben ser, en definitiva, contextualizados, sin perjuicio de su integración como pretensión de garantía universalizadora y colectiva.

Para salvar tal difícil equilibrio entre globalización y contextualización de los derechos fundamentales, el TEDH ha desarrollado la doctrina del margen de apreciación nacional, la cual viene a matizar el principio de integración que resulta del propio Preámbulo del Convenio ${ }^{4}$. Dicha doctrina constituiría un criterio de interpretación y aplicación de los derechos que vendría, a la postre, a funcionar no sólo como un elemento de auto constricción (self restraint) de los propios poderes revisores del Tribunal, sino como un verdadero instrumento de contextualización de los derechos, de manera que permita alcanzar un equilibrio entre universalización (europeización en nuestro caso) y contextualización. Una manera de que el marco de protección europea de los derechos y libertades atienda a elementos locales dentro del principio de universalidad ${ }^{5}$.

derechos fundamentales puede venir explicado por el temor a una aplicación descontextualizada, sobre todo, en un sistema de derechos que viene aún muy marcado por su experiencia histórica. Sobre dichos recelos, puede verse PASCUAL, M., «El TCF ante la integración europea. Últimas aportaciones», Comunicación presentada en el VIII Congreso de la Asociación de Constitucionalistas de España, 2010, pp. 1 a 21.

${ }^{3}$ Sobre la importancia de una visión histórica de los derechos, puede verse FERNÁNDEZ, E., «Los derechos humanos y la historia», en VVAA (Coords.), Constitución y derechos fundamentales, Madrid, CEPC, 2004, pp. 215 y ss.

${ }^{4}$ El principio de integración que se deriva del Preámbulo del Convenio promueve que los Estados miembros primen la interpretación de los derechos y libertades que promueva la integración política y social.

${ }^{5}$ Brokmann Haro, C., «La doctrina del margen de apreciación como instrumento de la protección de los derechos humanos», Derechos Humanos México. Revista del Centro Nacional de Derechos Humanos, n. ${ }^{\circ}$ 8, año 2008, p. 64. En similares términos, Ostrowsky 
En virtud de esta doctrina, los Estados miembros gozarían, respecto de la interpretación y aplicación de determinados derechos y libertades o, lo que viene a ser lo mismo, en el marco de la resolución de determinados conflictos, de un margen de determinación de la amplitud del derecho o de sus límites. Se trataría, en otras palabras, de un límite estructural a su aplicación que permite no entrar a revisar en ciertos casos la interferencia en el derecho si el fin de la restricción es legítimo, y la medida y la regulación son necesarias a ojos de las autoridades nacionales y todo ello no resulta irrazonable a la Corte ${ }^{6}$.

El margen de apreciación vendría a basarse en la idea de que cada sociedad tiene derecho a cierta libertad en el equilibrio de los derechos individuales y los intereses nacionales, así como en la resolución de los conflictos que surgen como resultado de diversas convicciones morales ${ }^{7}$. La doctrina está diseñada para proporcionar flexibilidad en la resolución de los conflictos que surgen de las diversas tradiciones sociales, políticas, culturales y jurídicas de los Estados contratantes en el contexto del CEDH, encontrándose, a este respecto, las autoridades nacionales en mejor posición que el TEDH para evaluar las circunstancias concretas de un caso $^{8}$.

A través del presente trabajo pretendemos hacer una análisis del manejo que el TEDH ha hecho en los últimos años de dicha doctrina de manera que trataremos de responder a la pregunta de si ha existido una efectiva integración europea de los derechos fundamentales o, ésta se ha visto sustancialmente matizada por la doctrina del margen de apreciación nacional y, también, abordaremos el debate acerca de la conveniencia de que el Tribunal mantenga, aún hoy, dicha doctrina.

\section{ORIGEN Y EVOLUCIÓN DE LA DOCTRINA DEL MARGEN DE APRECIACIÓN NACIONAL}

El origen de la doctrina del margen de apreciación no es normativo, sino jurisprudencial. Tal doctrina ni está incluida de forma expresa entre los preceptos del CEDH ni tampoco fue mencionada ni debatida en los trabajos preparatorios. Su inspiración parece situarse en las técnicas de la revisión judicial propias de los Estados, en particular, del Derecho administrativo francés y de su Consejo de Estado 9 . Su recepción por parte del TEDH se produce en el contexto de la previsión contenida explícitamente en el artículo 15 del CEDH que permite a los Estados derogar las obligaciones derivadas del Convenio en situaciones excepcionales, tales como la guerra u otros peligros públicos ${ }^{10}$.

señala que «The margin of appreciation is a valuable tool in that it legitimises international tribunals adjudicating on human rights, allows human rights norms to take on local flavour, but still preserves a concept of core or universal rights». Vid. OsTROWSKY, A. A., "What's so funny about peace, love, and understanding? how the margin of appreciation doctrine preserves core human rights within cultural diversity and legitimises International

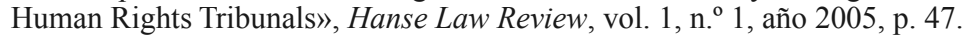


Como señala BENVENISTI, «The margins doctrine initially responded to concerns of national governments that international policies could jeopardize their national security. This may explain the initial application of the doctrine in the context of derogations from treaty obligations due to self-proclaimed states of national emergency» ${ }^{11}$. Y este origen, muy vinculado a supuestos de hecho muy excepcionales, puede que sea el que, en palabras de GARCÍA RocA, explique la oscuridad y tosquedad con la que ha sido construida la doctrina por parte del TEDH, como vamos a ver más adelante ${ }^{12}$.

El primer antecedente jurisprudencial de la doctrina puede situarse en el caso Grecia contra Reino Unido, 1956-57. Sin embargo, en esta decisión el término empleado por la Corte fue el de discretion, afirmándose que los Estados miembros «should be able to exercise a certain measure of discretion in assessing the extent strictly required by the exigencies of the situation».

El TEDH volverá a referirse a dicho margen de apreciación, sin emplear nominalmente el término, en el caso de la escuela lingüística belga contra Bélgica, 1968, recordando que existen aspectos de la vida social en los cuales las autoridades nacionales son libres de escoger las medidas que estimen apropiadas dentro de los aspectos regidos por la Convención ${ }^{13}$. El Tribunal aborda, al amparo del artículo 14 del Convenio que consagra la prohibición de discriminación, aquellos casos en lo que un Estado adopta una medida que suponga una diferencia de trato en el ejercicio de los derechos y libertades reconocidos

${ }^{6}$ GARcía RocA, J., «La muy discrecional doctrina del margen de apreciación nacional según el Tribunal Europeo de Derechos Humanos: soberanía e integración», Teoría y Realidad Constitucional, n. ${ }^{\circ}$ 20, año 2007, p. 121.

${ }^{7}$ Benvenisti, E., «Margin of Appreciation, Consensus, and Universal Standards», 31 Journal of International Law and Politics, vol. 31, n. ${ }^{\circ}$ 4, año 1999, p. 843.

${ }^{8}$ BAKIRCIOGLU, O., «The Application of the Margin of Appreciation Doctrine in Freedom of Expression and Public Morality Cases», German Law Journal, vol. 8, n. ${ }^{\circ}$ 7, pp. 711 y 712 .

${ }_{9}^{9}$ El pouvoir discrétionnaie que el Consejo otorga a las autoridades.

${ }^{10}$ GARCÍA ROCA, J., «La muy discrecional doctrina del margen de apreciación nacional ...», cit., pp. 121 y 122. En relación a la doctrina del margen de apreciación nacional en el ámbito de estas situaciones excepcionales, puede verse el caso Lawless contra Irlanda, 1961, sobre la presunta detención ilegal (medida de detención sin juicio) de un miembro del IRA, y en el que se concluye que no existe violación del artículo 7 del Convenio y que el encarcelamiento de G. R. Lawless se halla fundamentada en el derecho de derogación debidamente ejercitado por el Gobierno irlandés, conforme al artículo 15 del Convenio.

${ }^{11}$ Benvenisti, E., «Margin of Appreciation, Consensus, and Universal Standards», cit., p. 845 .

${ }^{12}$ García Roca, J., «La muy discrecional doctrina del margen de apreciación nacional ...», cit., p. 122.

${ }^{13}$ En el caso se discutía si algunas disposiciones de la legislación lingüística belga en materia de enseñanza respondían o no a las exigencias de los artículos 8 y 11 del Convenio; concretamente, se trataba de unos padres que pretendían que sus hijos recibieran su educación en lengua francesa pese a vivir en una región considerada por aquella legislación de lengua holandesa. 
por el Convenio. Considera el Tribunal que se llegaría a resultados absurdos si se diese al artículo 14 una interpretación tan amplia que implicara considerar contrarias al Convenio cada una de las numerosas disposiciones legales o reglamentarias que no aseguren a todos una completa igualdad de trato en el goce de los derechos y libertades reconocidos, ya que las autoridades nacionales competentes se ven a menudo frente a situaciones o problemas cuya diversidad reclama soluciones jurídicas distintas. Y así, importa, por tanto, buscar los criterios que permitan determinar si una diferencia de trato dada, relativa, por supuesto, al ejercicio de uno de los derechos y libertades reconocidas, contraviene o no el artículo 14. Para ello, el Tribunal acude al juicio de razonabilidad que constituye una práctica judicial de un gran número de países democráticos.

En definitiva, para el Tribunal, las autoridades nacionales siguen siendo libres para elegir las medidas que estimen apropiadas en las materias regidas por el Convenio, correspondiendo al Tribunal el control de conformidad de estas medidas con las exigencias del Convenio ${ }^{14}$.

En todo caso, en dicha resolución el Tribunal tampoco emplea nominalmente el término margen de apreciación naciona $1{ }^{15}$. Ello no ocurrirá hasta el caso Irlanda contra Reino Unido, 1978, en la que se declara que «By reason of their direct and continuous contact with the pressing needs of the moment, the national authorities are in principle in a better position than the international judge to decide both on the presence of such an emergency and on the nature and scope of derogations necessary to avert it. In this matter Article 15 para. 1 (art. 15-1) leaves those authorities a wide margin of appreciation ${ }^{16}$.

A partir de esta última decisión, la doctrina del margen de apreciación nacional se consolida como criterio de interpretación del Convenio y de las decisiones nacionales sobre derechos y libertades que proclama, e incluso, más allá de las suspensiones o restricciones de los derechos y libertades fundamentadas en peligros para la seguridad nacional según establece el artículo 15. El Tribunal parte de las situaciones previstas en dicho artículo del Convenio para, a continuación, conceder a los Estados miembros un amplio margen de selección de los supuestos en los que los Estados miembros podrían acudir a limitar los derechos y libertades proclamados en el Convenio sobre la base de criterios fundados en circunstancias específicas $^{17}$. De este modo, algunos autores señalan que en la doctrina del mar-

${ }^{14}$ Apartado 10 de la resolución.

${ }^{15}$ Puede verse también Lawless contra Irlanda, 1971.

${ }^{16}$ También se cita como precedente de la aplicación de la doctrina fuera de los supuestos previstos en el artículo 15, el caso Iversen contra Noruega, 1963.

17 TÜMAY, M., "The "margin of appreciation doctrine" developed by the case law of the European Court of Human Rights», Ankara Law Review, vol. 5, n. ${ }^{\circ}$ 2, año 2008, p. 207. 
gen de apreciación pueden destacarse dos etapas diferentes, una primera en la que la doctrina queda circunscrita a las previsiones del artículo 15 del Convenio, y una segunda en la que se consolida ya con carácter general como criterio de interpretación por parte del TEDH más allá del citado artículo $15^{18}$.

En todo caso, como ha destacado GREER, esta doctrina ha sido aplicada principalmente respecto de determinadas categorías de derechos de las consagradas en el Convenio, a saber: el derecho al disfrute pacífico de la propiedad prevista en el artículo 1 del Protocolo 1, el derecho a ser discriminado del artículo 14 o a las libertades personales consagradas en los artículos 8 a 11. Así, la doctrina no ha sido aplicada en relación al derecho a la vida que proclama el artículo 2 o en relación al derecho a no sufrir tratos inhumanos o degradantes o trabajos forzosos, de los artículos 3 y 4 respectivamente ${ }^{19}$. Ello encuentra su fundamento en que la aceptación de la doctrina en este campo produciría una relativización de lo que el propio Tribunal ha considerado valores fundamentales del sistema ${ }^{20}$.

Sin embargo, también se ha destacado que ello no impide, según se deduce de las decisiones del TEDH, que la doctrina no puede ser aplicada a cualquiera de los derechos consagrados en el Convenio ${ }^{21}$, aunque también habría que decir que a mayor precisión en la consagración del derecho por parte del Convenio, menor capacidad del TEDH de otorgar un amplio margen a los Estados miembros.

${ }^{18}$ Brokmann Haro, C., TÜmay, M., «La doctrina del margen de apreciación como instrumento de la protección de los derechos humanos», cit., pp. 68 a 72.

${ }^{19}$ GreER, S., «The interpretation of the European Convention on Human Rights: universal principle or margin of appreciation?», UCL Human Rights Review, vol. 3, año 2010, pp. 3 y 4. Vid. también, SpielmanN, D., «Allowing the Right Margin the European Court of Human Rights and the National Margin of Appreciation Doctrine: Waiver or Subsidiarity of European Review?», Centre for European Legal Studies, Working Papers Series, febrero 2012, p. 11. Contrariamente a dicha postura, Wada considera que en el caso Pretty contra Reino Unido, 2002, que versó sobre el artículo 2 del Convenio y, más concretamente, sobre si tal precepto amparaba la solicitud de auxilio al suicidio de un paciente que sufría una enfermedad incurable, el Tribunal sí acude a la doctrina del margen pese a que no mencione literalmente la misma en la resolución. Vid. WADA, E., «A Pretty picture: the margin of appreciation and the right to assisted suicide», Loyola of Los Angeles International and Comparative Law Review, vol. 27, año 2005, pp. 288 y 289.

${ }^{20}$ VASEL, J. J., «El margin of appreciation como elemento clave en el Derecho constitucional europeo», Revista de Derecho constitucional europeo, n. ${ }^{\circ}$ 11, enero-junio 2009.

${ }^{21}$ Macdonald, R. St J., "The Margin of Appreciation in the Jurisprudence of the European Court of Human Rights», en International Law at the Time of its Codification, Essays in Honour of Judge Roberto Ago, Giuffrè, Milan, 1987, p. 192, citado en GreER, S., «The interpretation of the European Convention on Human Rights: ...», cit., p. 4; y «The Margin of Appreciation», en Macdonald, R. St J., Matcher, F. y Petzold, H. (Eds.), The european system for the protection of human rights, Springer, Londres, 1993, p. 192. 


\section{FUNDAMENTO Y ELEMENTOS INTEGRANTES DE LA DOCTRINA}

A la vista de la evolución que acabamos de comentar que se produce en la doctrina de margen de apreciación, uno de los criterios que maneja principalmente el TEDH a la hora de recurrir a ella fuera de la previsión contenida en el artículo 15 del Convenio será la ausencia de un consenso entre los diferentes Estados parte sobre determinados derechos y sus límites ${ }^{22}$. De este modo, allí donde no exista consenso, el TEDH ha de restringir su poder de revisión, no pudiendo imponer un criterio único o uniforme. Podría decirse que donde no existe un criterio común entre los Estados miembros, no puede imponerlo el TEDH.

Un ejemplo de ello, lo encontramos en Handyside contra Reino Unido, 1976, caso que versó sobre la condena por atentado a la moral pública cometido por el autor de un libro editado bajo el título The Little Red Schoolbook. En su decisión, el TEDH declara, acerca de la falta de un criterio común entre los Estados miembros sobre el concepto de moralidad pública que «it is not possible to find in the domestic law of the various Contracting States a uniform European conception of morals. The view taken by their respective laws of the requirements of morals varies from time to time and from place to place, especially in our era which is characterised by a rapid and far-reaching evolution of opinions on the subject. By reason of their direct and continuous contact with the vital forces of their countries, State authorities are in principle in a better position than the international judge to give an opinion on the exact content of these requirements as well as on the "necessity» of a «restriction» or "penalty» intended to meet them» (apartado 48) ${ }^{23}$.

Sin embargo, en Dudgeon contra Reino Unido, 1981-83, en el que también se abordó la existencia o no de un concepto común de moralidad pública, aunque, en este caso, en el ámbito de las relaciones homosexuales, el TEDH consideró que «there is now a better understanding, and in consequence an increased tolerance, of homosexual behavior to the extent that in the great majority of the member States of the Council of Europe it is no longer considered to be necessary or appropriate to treat homosexual practices of the kind now in question as in themselves a matter to which the sanctions of the criminal law should be applied; the Court cannot overlook the marked

${ }^{22}$ Balbosa Delgado, F. R., «Los límites a la doctrina del margen nacional de apreciación en el Tribunal Europeo y la Corte Interamericana de Derechos Humanos: intervención judicial en torno a ciertos derechos de las minorías étnicas y culturales», Revista Derecho del Estado, n. ${ }^{\circ}$ 26, enero-junio 2011, p. 112; y OstrowSKY, A. A., "What's so funny about peace, love, and understanding? ...», cit., p. 52.

${ }_{23}$ Puede verse un interesante comentario sobre esta decisión, en BAKIRCIOGLU, O., «The Application of the Margin of Appreciation Doctrine in Freedom of Expression and Public Morality Cases», cit., p. 716. 
changes which have occurred in this regard in the domestic law of the member States $\gg{ }^{24}$.

De este modo, si el fundamento de la doctrina principal fuera ya dicha ausencia de consenso sobre la regulación de determinados derechos, el Tribunal habría de explorar en cada supuesto objeto de enjuiciamiento no sólo la regulación contenida en el propio Convenio, sino también la que se establece en los diferentes Estados miembros. El recurso al método comparativo habría de ser frecuente en el enjuiciamiento por parte del Tribunal ${ }^{25}$.

Así ocurrió, por ejemplo, en el caso National Union of Belgian Police contra Bélgica, 1975, en el que el TEDH no apreció infracción del artículo 11 del Convenio por el hecho de que el Estado belga no estableciera en su legislación la obligación de cumplir con el trámite de audiencia respecto de todos los sindicatos, sino sólo de aquellos que tuvieran determinada representatividad. El Tribunal tuvo en cuenta, para concluir que no hubo tal infracción, que el resto de Estados miembros no habían establecido un derecho de consulta general respecto de todas las organizaciones sindicales. La falta de consenso determinaba que el artículo 11 había de ser interpretado en el sentido de que se concedía a los Estados miembros un amplio margen de apreciación para alcanzar el objetivo pretendido con dicho precepto ${ }^{26}$. El mismo argu-

${ }^{24}$ Sin embargo, en el caso Fretté contra Francia, 2002, que versó sobre el rechazo por parte de las autoridades francesas a que una persona que había reconocido su homosexualidad pudiera adoptar un niño, el Tribunal rechazó que se hubiera producido vulneración alguna del artículo 14 del Convenio sobre la base de la ausencia de consenso entre los Estados miembros acerca de la posibilidad de que los homosexuales puedan adoptar. Vid. SRONE, T. W., «Margin of appreciation gone awry: the European Court of Human Rights' implicit use of the precautionary principle in Fretté v. France to Backtrack on Protection from Discrimination on the Basis of Sexual Orientation», Connecticut Public Interest Law Journal, vol. 3, n. ${ }^{\circ}$ 1, año 2003, p. 223. Curiosamente, años después, en un caso también de adopción por una persona que también había reconocido su homosexual, E.B. contra Francia, 2008, sí admitió que se había producido vulneración de los artículos 8 y 14 del Convenio, aunque, como expresa el propio Tribunal, no hay contradicción con la decisión anterior al concurrir elementos diferentes en ambos casos. Se recoge un comentario muy completo de este último caso y su comparación con lo resuelto en Fretté en MARCOS MARTín, T., «La adopción por parte de persona homosexual y su relación con el derecho a la vida familiar y la no discriminación por razón de sexo. comentario a la sentencia del TEDH de 22 de enero de 2008 (E.B. c. Francia, asunto n ${ }^{\circ}$ 43546/02)», Revista General de Derecho Europeo, n. ${ }^{\circ}$ 16, año 2008, pp. 1 a 14. Parece que esta resolución y la posterior Kozak contra Polonia, 2010, sobre el derecho a subrogarse un homosexual en el arrendamiento del apartamento en el que convivía con su pareja, permiten afirmar que el Tribunal ha reducido notablemente el margen de apreciación nacional en el ámbito de las diferencias de trato por orientación sexual.

${ }^{25}$ OSTROWSKY recuerda que también el Tribunal Supremo de Estados Unidos ha desarrollado una doctrina similar a la doctrina del margen de apreciación nacional a partir del criterio del consenso, rational basis test. Vid. OstrowsKY, A. A., "What's so funny about peace, love, and understanding? ...», cit., pp. 60 a 63.

${ }^{26}$ Apartado 39. 
mento fue manejado en el caso Engel y otros contra Países Bajos, 1976, en relación a la falta de consenso de los Estados miembros sobre la exigencia de que el régimen disciplinario de los militares no estableciera diferentes sanciones en función del rango del sujeto ${ }^{27}$.

También se ha acudido al criterio de la falta de consenso en la resolución de los casos sobre la prohibición del velo a los que ha tenido que enfrentarse el TEDH. Así, tanto en Dahlab contra Suiza, 2011, como en Sahin contra Turquía, 2004, la Corte aplicó un amplio margen de apreciación nacional en parte porque no existía consenso o, éste, al menos, era mínimo entre los Estados miembros acerca del hecho de la prohibición del velo. Además, para la Corte, el margen de apreciación es particularmente apropiado cuando este se relaciona con la regulación del uso de símbolos religiosos en los centros de educación $^{28}$.

Algún sector de la doctrina española ha planteado que el concepto de consenso europeo al que acude, como estamos viendo, el TEDH se está viendo recientemente sustituido por el de tendencia internacional continuada ${ }^{29}$. Así, el Tribunal ha puesto de manifiesto que «... menos importancia a la ausencia de elementos que indiquen un consenso europeo en relación con la manera de resolver los problemas jurídicos y prácticos que a la existencia de elementos claros e incuestionables que revelan una tendencia internacional continuada no sólo en pos de una aceptación social creciente de los transexuales sino también orientada al reconocimiento jurídico de la nueva identidad sexual de los transexuales operados $\rangle^{30}$. Así pues, parece que se relativiza el criterio del consenso y, por ende, la doctrina del margen, si se aprecia, no ya un parecer unánime o, al menos, mayoritario entre los Estados miembros, sino una apreciable tendencia continuada en las legislaciones de los Estados miembros que permite pronosticar que, no existiendo aún consenso sobre la materia, parece que habrá de existir en un periodo de tiempo no muy dilatado.

Por otro lado, en la evolución de la doctrina del margen de apreciación nacional puede observarse que junto al elemento de la falta consenso subyace también la idea de que en el sistema europeo de protección de los derechos los principales obligados son los propios Estados, debiendo actuar

${ }^{27}$ Apartado 72.

${ }^{28}$ OSTROWSKY, A.A., «What's so funny about peace, love, and understanding? ...» cit., p. 55. La Corte ha acudido también a la doctrina del margen en otros dos casos más recientes sobre el velo islámico, Dogru contra Francia y Kervanci contra Francia, ambos de 2008. En dichas resoluciones la Corte señaló que el principio de laicidad es principio fundamental del Estado francés de manera que es preciso concederle un amplio margen de apreciación en la regulación de las relaciones entre el Estado y las religiones.

${ }^{29}$ GonzÁlez VegA, J. A., «Derecho a la identidad sexual y Convenio Europeo: la posición del Tribunal Europeo de Derechos Humanos», Revista General de Derecho Europeo, n. ${ }^{\circ} 1$, mayo 2003 , pp. 17 y 18. 2002 .

${ }^{30}$ Casos Christine Goodwin contra Reino Unido e I. contra Reino Unido, ambos de 
el TEDH tan sólo para asegurar que dichos Estados han permanecido dentro de sus límites ${ }^{31}$. Y tal idea de subsidiariedad supone también que el correspondiente Estado miembro ha de encontrarse en una mejor posición que el propio Tribunal para poder explicar las excepciones al régimen general de los derechos y libertades que vienen fundamentadas en elementos histórico-culturales.

Dicho principio de subsidiariedad tampoco aparece explícitamente recogido en el Convenio, aunque se deduciría de sus artículos 1,13 y 35 y ha sido igualmente reconocido a través de la jurisprudencia del TEDH. Así, en el ya citado caso Handyside contra Reino Unido, 1976, el Tribunal declaró que «it is in no way the Court's task to take the place of the competent national courts but rather to review the decisions they delivered in the exercise of their power of appreciation» (apartado 50), añadiendo también que «The Court points out that the machinery of protection established by the Convention is subsidiary to the national systems safeguarding human rights ... The Convention leaves to each Contracting State, in the first place, the task of securing the rights and liberties it enshrines» (apartado 48) ${ }^{32}$.

En todo caso, en el caso Handyside, como ya hemos visto antes, el TEDH acudió también al criterio de la falta de consenso en relación a un concepto común de moralidad pública, de modo que los Estados miembros habrán de gozar de un margen de apreciación a los efectos de poder limitar los derechos y libertades consagrados en el Convenio sobre la base del interés basado en la moral pública. Este criterio abre un amplio espacio de apreciación nacional a uno de los que tradicionalmente ha constituido el principal límite a los derechos y libertades.

Así pues, más allá de explorar comparativamente si existe un consenso sobre la materia por parte de los Estados miembros, el Tribunal habrá también de valorar en qué medida son razonables los límites impuestos por el Estado miembro. Ello, vendrá a otorgar un papel protagonista al principio de proporcionalidad, de manera que el Tribunal habrá de acudir a dicho principio a los efectos de valorar la limitación impuesta por el Estado miembro, es decir, habrá de enjuiciar si la medida adoptada por el Estado miembro es razonable, idónea y adoptada de buena fe, aunque, sin olvidar, obviamente, si la misma

${ }^{31}$ Como apunta con certeza IMBERT, la internacionalización de los derechos no debe, so pena de hacernos pensar que los Estados nacionales han perdido ya toda obligación, diluir ni hacer desaparecer la responsabilidad de los jueces nacionales, ya que la protección eficaz de los derechos es obligación que incumbe en primer lugar al Estado miembro y a sus Tribunales, debiendo intervenir la instancia internacional como una última medida. Vid. Imbert, P-H., «Los derechos humanos en la actualidad», en PÉreZ-LuÑo, A.-E., Derechos humanos y constitucionalismo ante el tercer milenio, Madrid; Marcial Pons, 1996, pp. 76 y 77.

32 TÜMAY, M., «The «margin of appreciation doctrine» developed by the case law of the European Court of Human Rights», cit., pp. 203 y 204. 
se muestra también respetuosa con la obligaciones asumidas por el Estado miembro a través de la ratificación del Convenio ${ }^{33}$.

Sin embargo, Greer recuerda que la conexión que pudiera existir entre la doctrina del margen de apreciación nacional y el principio de proporcionalidad ha de ser manejada con cautela, ya que el propio TEDH tampoco ha sido muy preciso a la hora de manejar este principio y a la hora de fundamentar el mismo en los tres elementos que lo integran. Así, en ocasiones el Tribunal hace un uso del principio sin ajustarse necesariamente a dichos tres elementos y refiriéndose a una mera concepción poco concreta del equilibrio (balancing, en los términos empleados por la doctrina estadounidense) entre el sacrificio del derecho individual, por un lado, y el beneficio para el interés general, por el otro ${ }^{34}$.

El recurso al principio de subsidiariedad que se observa en la evolución de la doctrina conectaría, además, con meras razones de política judicial, y ello, al ofrecer el margen de apreciación nacional la flexibilidad necesaria para evitar los daños que podrían derivarse de un enfrentamiento entre el TEDH y los Tribunales nacionales sobre sus respectivas esferas de autoridad ${ }^{35}$. Así, algún autor ha señalado que la doctrina constituye uno de los principales salvavidas desarrollados por la Comisión y el Tribunal para reconciliar la eficacia del Convenio y los poderes soberanos y responsabilidades de los gobiernos en democracia ${ }^{36}$. Y, porque, como nos recuerda GERARDS «Given the lack of erga omnes effect and supremacy of the decisions of the ECtHR, the

${ }^{33}$ Ibidem, p. 213.

${ }^{34}$ GREER, S., «The interpretation of the European Convention on Human Rights: ...», cit., pp. 11 y 12. Greer cita, como ejemplos de dicho uso poco preciso del principio de proporcionalidad, los casos Grande Oriente d'Italia di Palazzo contra Italia, 2002, Piermont contra Francia, 1995, Klass contra Alemania, 1994, Barfod contra Dinamarca, 1991, Gaskin contra Reino Unido, 1990. También critica el uso que el Tribunal Europeo ha hecho en ocasiones del principio de proporcionalidad en relación con la doctrina del margen de apreciación nacional Butler, la cual considera que el Tribunal acude al margen de apreciación para efectuar una ponderación entre el interés individual y el bien común que es más propio del principio de proporcionalidad. Vid. BUTLER, P., «Margin of appreciation-A note towards a solution for the Pacific?», Victoria University of Wellington Law Review, vol. 39, año 2008, p. 703.

${ }^{35}$ Benvenisti, E., «Margin of Appreciation, Consensus, and Universal Standards», cit., p. 846. Interesa recordar a este respecto, la reunión que los cuarenta y siete miembros del Consejo celebraron en Suiza en febrero de 2010, en la que se aprobó una declaración conjunta invitando al Tribunal a recordar la naturaleza subsidiaria del control que le corresponde al amparo del Convenio. Tur Ausina conecta dicha reunión con el revuelo que ocasionó la primera Sentencia en el caso Lautsi contra Italia, 2009, sobre los crucifijos en las aulas de las escuelas públicas, que como es bien conocido fue revocada por la Gran Sala en posterior decisión de 2011. Vid. Tur AsinA, A., «La simbología religiosa desde planteamientos inclusivos democráticos en el ámbito educativo» en SoUTO PAZ, J.A., (Dir.), Educación y libertad, Madrid; Dykinson, 2012, p. 144.

${ }^{36}$ WALDOCK, H., «The Effectiveness of the System Set Up by the European Convention of Human Rights», Human Rights Law Journal, año 1980, p. 9, citado en M. TÜMAY, «The «margin of appreciation doctrine» developed by the case law of the European Court of Human Rights», cit., p. 207. 
domestic effect of the Strasbourg judgments is even more precarious and is strongly dependent on the status of the Convention and the Court's judgments in the national legal system» ${ }^{37}$, de manera que el TEDH «will have to pay careful attention to national sensitivities and differences in order to retain its legitimacy and to guarantee voluntary compliance with their judgments» ${ }^{38}$.

El Tribunal es consciente de que los Estados miembros presentan tanto circunstancias como sensibilidades diferentes que no pueden ser desatendidas, más aún, al amparo del principio de subsidiariedad que rige la labor revisora del TEDH ${ }^{39}$. Además, este poder revisor ha de ser especialmente cauto, necesitándose contar con poderosas razones (strong reasons) en aquellos casos en los que el conflicto haya sido resuelto por una Corte nacional superior ${ }^{40}$.

Por último, otro elemento al que ha atendido con frecuencia el TEDH en orden a valorar la extensión de la doctrina del margen viene constituido por la mayor o menor conexión del derecho, bien con la dignidad de la persona, bien con el principio de Estado democrático. Así, por ejemplo, en aquellos derechos que guarden una estrecha relación con el principio de democracia, de manera que se muestren como elementos indispensables del mismo, el margen será más limitado que respecto de aquellos otros en los que no se aprecie tal conexión. Entre tales derechos, se ha destacado la libertad de expresión que presenta un doble fundamento, subjetivo que conecta con la dignidad humana y libre desarrollo de la personalidad, y objetivo al constituir un elemento imprescindible de la democracia ${ }^{41}$.

GARCÍA RocA, en relación con este factor relativo a la mayor o menor conexión del derecho objeto de discusión con la dignidad y el principio de democracia, sistematiza gráficamente el uso que el TEDH ha hecho de la doctrina del margen de apreciación nacional a través de tres círculos concéntricos que vendrían predeterminados por la naturaleza de los derechos objeto de discusión ${ }^{42}$ :

${ }^{37}$ Gerards, J., «Towards an European doctrine of deference?», discussion paper, The Margin of Appreciation Doctrine of the ECtHR, Expert seminar, Ghent, 21 May 2010, p. 5.

${ }^{38}$ Ibidem, p. 4.

${ }^{39}$ En especial, vid. el caso de la escuela lingüística belga contra Bélgica, 1968 (apartado $10)$.

${ }^{40}$ Spielmann, D., «Allowing the Right Margin the European Court of Human Rights and the National Margin of Appreciation Doctrine: ...», cit., pp. 23 y 24.

${ }^{41}$ Esta doble dimensión ha sido también reconocida por nuestro Tribunal Constitucional en su Sentencia 25/1981. A esa misma dimensión objetiva se ha referido Haberle cuando señala que los derechos fundamentales son rasgos esenciales de la democracia, sin cuyo reconocimiento y ejercicio ésta no puede existir. Vid. HÄBERLE, P., «Die Wesengehaltsgarantie des Artikel 19 Abs. 2 Grundgesetz», p. 17, citado por SolózoBAL, J.J., «La libertad de expresión desde la teoría de los derechos fundamentales», Revista Española de Derecho Constitucional, n. ${ }^{\circ}$ 32, mayo-agosto 1991, p. 93.

${ }^{42}$ GARCía RocA, J., «La muy discrecional doctrina del margen de apreciación nacional ...», cit., p. 127. 
a) Una primera categoría de derechos en los que el margen de apreciación concedida a los Estados es muy amplia, siendo el control europeo poco intenso (círculo externo). Ello tendría lugar con ocasión de los derechos de propiedad con escaso contenido esencial y una intensa configuración legal. Ocurriría también lo mismo con las diferentes modalidades del derecho a un proceso equitativo muy abiertas a su configuración legal en los procesos.

b) Una segunda categoría de derechos en la que se situarían los derechos absolutos, como la vida, o los derechos que conectan con el principio de Estado democrático y en la que el margen de apreciación nacional será muy pequeño (circulo interno).

c) Y, por último, una tercera categoría en la que se situarían el resto de derechos y en los que el margen de apreciación nacional puede variar (circulo intermedio).

El propio GARCÍA RoCA admite que tal intento de sistematización no se cumple siempre, ya que en algunos casos el propio Tribunal, pese a que admite un amplio margen de apreciación nacional, acaba por aplicar una solución contraria a dicha premisa. Es decir, un amplio margen nacional en teoría, pero, en algunos casos, compatible con un control europeo en la práctica bastante intenso ${ }^{43}$.

En todo caso, a la vista de esta sistematización podría afirmarse ya que la discrecionalidad o, incluso, arbitrariedad por parte del TEDH en el recurso a la doctrina del margen de apreciación nacional no es tan aparente, en la medida que la respuesta dependerá, no tanto de los diferentes elementos a los que se acuda para adoptar la solución, sino a la mayor o menor conexión del derecho objeto de discusión con la dignidad de la persona. De este modo, cuando un derecho muestre una conexión directa con la dignidad humana, el margen de apreciación nacional será mínimo o inexistente (véase, vida, libertad, etc ...). Por el contrario, cuando el derecho, por su falta de conexión con la dignidad constituya un derecho de mera configuración legal, el margen será muy amplio.

Un ejemplo paradigmático de cómo la conexión con la dignidad determina una evidente reducción del margen lo encontramos en el caso Tyrer contra el Reino Unido, 1978. En dicho caso el Gobierno demandado adujo en defensa de su posición que los castigos corporales no repugnaban a la opinión pública británica. Sin embargo, la Corte sostuvo, contrariamente, que no podía dejar de estar influida por los desarrollos y estándares comúnmente aceptados en este terreno según las políticas criminales de los Estados miembros del Consejo de Europa y, de este modo, la práctica tradicional del castigo corporal en las escuelas británicas podía acaso no repugnar a los habitantes de la Isla de Man, pero molestaba por denigrante a la sensibilidad mayoritaria del resto de los europeos. En todo caso, vemos como no es sólo el criterio de la conexión del derecho con la

${ }^{43}$ Ibidem., p. 128. 
dignidad humana el que determina la respuesta que da el TEDH, sino también el criterio del consenso entre los Estados miembros.

En resumen, podrían destacarse los siguientes factores a los que el TEDH ha acudido para justificar el recurso a la doctrina del margen de apreciación nacional:

En primer lugar, la ausencia de una base normativa común (consenso) entre los Estados miembros. Este factor podemos considerar que constituye el principal elemento que maneja el Tribunal, aunque es frecuente que no lo haga aisladamente, sino en conjunción con alguno de los otros.

En segundo lugar, la existencia de circunstancias particulares como pueden ser una situación de emergencia o de peligro (recuérdese que la doctrina nace ligada al artículo 15 del Convenio), o la especial susceptibilidad o sensibilidad nacional en la materia, o lo que viene a ser lo mismo, diferentes realidades sociales sobre las que las normas convencionales vayan a ser aplicadas ${ }^{44}$.

En tercer lugar, la mera oportunidad de restringir el poder revisor por parte del TEDH, permitiendo un mayor margen de decisión nacional con el fin de evitar conflictos con los Estados miembros.

Por último, la mayor o menor conexión del derecho concreto en discusión con la dignidad humana y libre desarrollo de la personalidad o con el principio democrático.

No es inhabitual, como ya hemos apuntado, que el TEDH acuda conjuntamente a varios de los factores mencionados para conceder a los Estados miembros un amplio margen de apreciación nacional en ámbitos concretos. Así, en el caso Open Door and Dublin Well Woman contra Irlanda, 1992, el Tribunal declaró que «It acknowledges that the national authorities enjoy a wide margin of appreciation in matters of morals, particularly in an area such as the present which touches on matters of belief concerning the nature of human life. As the Court has observed before, it is not possible to find in the legal and social orders of the Contracting States a uniform European conception of morals, and the state authorities are, in principle, in a better position than the international judge to give an opinion on the exact content of the requirements of morals as well as on the «necessity» of a «restriction» or "penalty» intended to meet them» (apartado 68).

\section{LA PRINCIPAL CRÍTICA A LA DOCTRINA: SU FALTA DE SISTE- MATIZACIÓN}

La principal crítica que se ha efectuado a la doctrina del margen de apreciación nacional viene referida a su imprecisión ${ }^{45}$, y ello, fundamentalmente, porque los factores a los que ha venido atendiendo el Tribunal en su desarrollo

${ }^{44}$ ShanY, Y., «Toward a General Margin of Appreciation Doctrine in International Law?», The European Journal of International Law, vol. 16, n. ${ }^{\circ}$ 5, año 2005, p. 927.

${ }^{45}$ GARcía RocA, J., «La muy discrecional doctrina del margen de apreciación nacional ...», cit., pp. 124 y 125 . 
de la doctrina no han sido claramente sistematizados, de manera que en cada caso concreto no puede preverse a qué elemento o elementos habrá de acudirse para su resolución ${ }^{46}$. Así, se viene a otorgar al Tribunal un amplio margen de discrecionalidad con los efectos directos que ello produce sobre el principio de seguridad jurídica. Se echa de menos una construcción abstracta y general sobre lo que puede considerarse que es o no común respecto de cada derecho. Incluso, se afirma que el Tribunal emplearía dicha doctrina como mera herramienta para hacer, en determinados casos, dejación de sus funciones de supervisión ${ }^{47}$.

En definitiva, se ha destacado la importancia de que el TEDH establezca unos criterios sólidos y previsibles para la propia pervivencia del modelo europeo de protección de los derechos ${ }^{48}$. Pero, ¿no es ello así en muchos otros casos o respecto de otras reglas de interpretación y solución de los conflictos? ¿No es menos cierto que la resolución de los conflictos entre derechos o entre éstos y los intereses generales no ha de estar presidida necesariamente por una excesiva casuística, de manera que las circunstancias concurrentes en cada caso pueden marcar una solución diferente?

Para Tümay las críticas a la doctrina olvidan la importancia que en el marco de decisiones del TEDH tiene el hecho de que el Convenio sea considerado un instrumento vivo (living instrument) que tiene que ser aplicado en un contexto supranacional con múltiples sistemas legales, políticos y económicos, con diferentes costumbres y hábitos y con otros factores relevantes como son las diferentes creencias ideológicas y religiosas. Por ello, la aplicación del Convenio ha de mostrar la adecuada flexibilidad que le permita acomodarse a todas estas diferencias y obtener, en cierta manera, el propio refrendo de los Estados miembros y sus Tribunales nacionales. E, igualmente, las críticas olvidan que las cláusulas contenidas en el Convenio aparecen redactadas de manera amplia e imprecisa, de modo que su aplicación a un supuesto de hecho concreto exige por parte del Tribunal una labor interpretativa $\mathrm{y}$, por ende, contextualizadora ${ }^{49}$.

${ }^{46}$ Ibidem, p. 126.

${ }^{47}$ BAKIRCIOGLU, O., «The Application of the Margin of Appreciation Doctrine in Freedom of Expression and Public Morality Cases», cit., p. 731. En sentido contrario, el propio Tribunal ha dejado de aplicar la doctrina del margen cuando ha considerado que en algún caso en el que encontraba pleno fundamento su aplicación en atención a su línea jurisprudencial podría alcanzarse una decisión, en apariencia, injusta. Como ejemplo de ello, se ha citado el caso Muñoz Díaz contra España, 2009, que versó sobre el derecho a la pensión por viudedad de una mujer de etnia gitana. Vid. MATÍA PORTILLA, F. J., «Condena por una discriminación inexistente (Tribunal de Estrasburgo y matrimonio gitano», $R E D C$, n. ${ }^{\circ}$ 92, mayo-agosto 2011, p. 381.

${ }^{48}$ Ibidem, p. 732.

49 TÜMAY M., «The «margin of appreciation doctrine» developed by the case law of the European Court of Human Rights», cit., p. 214. En similares términos se expresa Borkmann Haro quien considera que la doctrina del margen permite una aplicación dinámica del Convenio como instrumento vivo. Vid. Brokman HARO, C., «La doctrina del margen de apreciación como instrumento de la protección de los derechos humanos», cit., p. 82. 
Ello, además, ha sido reconocido por el propio TEDH que ha señalado que «the scope of this margin of appreciation is not identical in each case but will vary according to the context ... Relevant factors include the nature of the Convention right in issue, its importance for the individual and the nature of the activities concerned $\gg{ }^{50}$.

Además, puede también afirmarse que la falta de solidez de la doctrina del margen de apreciación nacional no resulta verdaderamente preocupante para el mantenimiento del sistema europeo de protección de los derechos porque los propios Estados miembros vienen realizando esfuerzos por incorporar a sus sistemas jurídicos internos tanto los principios y reglas que consagra el Convenio como la propia doctrina del TEDH. Incluso, tal doctrina permite que tal inserción a nivel estatal se desarrolle bajo la confianza de que determinados intereses o valores nacionales no se verán en peligro por ello, lo que, a la postre, redunda en favor de la europeización de los derechos ${ }^{51}$. Se trata, pues, de una herramienta flexible que permite superar las concretas dificultades para la implementación del Convenio. En palabras de OsTROWSKY, «the margin of appreciation serves a human rights tribunal well in finding a compromise between an essentialist morality (universalism) and legitimising flexibility (relativism) $\rangle^{52}$.

GREER considera que no existe una contradicción entre la pretensión de europeizar los derechos y libertades y admitir, al mismo tiempo, la doctrina del margen de apreciación nacional. Tal planteamiento encierra una falsa contradicción porque si los derechos y libertades que se consagran en la Convención están expresados en términos amplios y universales, resulta evidente que no hay interpretaciones objetivamente válidas sobre cuál es su significado para todo momento y lugar. La labor del Juez no sólo será pues determinar qué significan tales derechos y libertades con carácter general, sino cuál es su significado y efectos en cada contexto nacional ${ }^{53}$.

Para MAHONEY la doctrina del margen de apreciación nacional operaría como la línea divisoria entre aquello que exige ser europeizado y aquello que no. Constituye un instrumento interpretativo que vendría a trazar una línea divisoria entre las cuestiones que debe decidir cada comunidad nacional y las que tienen suficiente relevancia o carácter fundamental como para necesitar una solución homogénea en el marco del Convenio ${ }^{54}$.

${ }^{50}$ Vid. Caso Buckley contra Reino Unido, 1996, apartado 74.

${ }^{51}$ Macdonald, R. St J., «The Margin of Appreciation», en Macdonald, R. St J., Matcher, F. y Petzold, H. (Eds.), The european system for the protection of human rights, cit., p. 733.

${ }^{52}$ Ostrowsky, A. A., "What's so funny about peace, love, and understanding? ...», cit., p. 58.

${ }^{53}$ GreER, S., «The interpretation of the European Convention on Human Rights: ...», cit., p. 1.

${ }_{54}$ Mahorney, P., «Marvellous richness diversity or individual cultural relativism Human Rights Law Journal, vol. 19, núm. 1, 30 de abril de 1998, p. 1. 
En todo caso, aun admitiendo que los factores a los que atiende el TEDH en la aplicación de la doctrina del margen han ido poco a poco aclarándose, pudiéndose ya hablar de cierta previsibilidad acerca de la aplicación y extensión de la doctrina, es cierto también que algunos de dichos factores no están todavía dotados de una gran precisión. Entre ellos, destacaría el factor del consenso, habiéndose señalado que no existe actualmente un concepto claro acerca de lo que el Tribunal entiende por falta de consenso entre los Estados miembros ${ }^{55}$.

\section{CONTEXTUALIZACIÓN DE LOS DERECHOS EN LA UNIÓN EU- ROPEA: EL CASO OMEGA}

La contextualización de los derechos y libertades que, a la postre, provoca la doctrina del margen de apreciación nacional puede apreciarse más allá del TEDH, habiendo alcanzado también a la propia Unión Europea. A este respecto, encontramos un ejemplo paradigmático en el denominado caso Omega resuelto por el Tribunal de Justicia en $2004^{56}$.

El Caso Omega versó sobre la prohibición por el Estado alemán de un juego que se desarrollaba en un local de ocio, denominado laserdromo, y que consistía en jugar a disparar a un contrincante. Los jugadores utilizaban unos aparatos de láser en forma de ametralladora y unos chalecos que tenían unos receptores que funcionaban como objetivo y que permitían conocer cuando uno de los jugadores era alcanzado por otro en una parte vital de su cuerpo o calcular el número de impactos que conseguía cada jugador. Era un juego de matar, en boga en otros países, como Reino Unido y España, y conocido bajo el anglicismo de Paintball en su versión con bolas de pintura que marcan al contrincante. Las autoridades alemanas consideraron que la actividad llevada a cabo por el laserdromo constituía una amenaza para el orden público debido a que la explotación comercial de juegos de entretenimiento con homicidios simulados menoscaba un valor fundamental consagrado por la Ley Fundamental de Bonn, la dignidad humana.

La discusión jurídica llevó necesariamente al Tribunal a plantearse por qué un juego que era permitido en otros países de la propia Unión Europea, era prohibido en Alemania. Ante tal cuestión, el Tribunal consideró que la decisión estaba justificada en cuanto vino fundada en la dignidad humana que en Alemania posee un régimen singular en cuanto constituye un derecho fun-

${ }^{55}$ OstrowsKy, A. A., «What's so funny about peace, love, and understanding? ...», cit., p. 58. Vid. también, GonZÁlez VeGA, J. A., «Derecho a la identidad sexual y Convenio Europeo: la posición del Tribunal Europeo de Derechos Humanos», cit., pp. 9 a 12.

${ }^{56}$ De Miguel BÁRcenA señala que este caso, junto al caso Schmidberger de 2003, han supuesto, a la postre, el triunfo en la UE de los derechos fundamentales no económicos. Vid. De Miguel BÁrcenA, J., «Los derechos fundamentales como manifestación de la Europa federal», Comunicación presentada en el VIII Congreso de la Asociación de Constitucionalistas de España, 2010, p. 7. 
damental autónomo, no siendo indispensable que la medida restrictiva adoptada por las autoridades de un Estado miembro corresponda a una concepción compartida por el conjunto de los Estados miembros en cuanto a las modalidades de protección del derecho fundamental o interés legítimo controvertido. En todo caso, en la decisión del Tribunal influyó más el hecho de que la dignidad, con independencia de que estuviera consagrada como derecho fundamental autónomo en el orden constitucional alemán, gozaba también de protección en el ámbito europeo.

SÁNCHEZ LORENZO que analiza en profundidad el caso considera que el fundamento de la decisión del Tribunal viene determinado por las circunstancias históricas de Alemania, lo que otorga a la dignidad humana una especial consideración o sensibilidad. Su conclusión es que «hay cosas a las que se puede jugar en el Reino Unido y a las que no se puede jugar en Alemania, sólo por el hecho de que la experiencia histórica colectiva es muy diferente en ciertos puntos. Sobre la conciencia colectiva alemana pesa -no cabe dudael recuerdo del holocausto, la banalización de la vida humana en uno de los pueblos más cultos de la tierra, el sentimiento de responsabilidad colectiva por el frío asesinato -como si fuera un juego-de millones de seres humanos. Esa experiencia histórica forma parte de una cultura peculiar, de una hermenéutica del entorno singular, de una escala de valores particular. En otros contextos la medida prohibitiva puede parecer una exageración, porque la experiencia histórica no contraindica ciertos juegos, que pueden ser sólo juegos. Pero, a matar, en Alemania no se juega» ${ }^{57}$.

Como puede comprobarse no es la ausencia de consenso sobre el régimen de los derechos y libertades por parte de los Estados miembros lo que justifica un trato diferente, sino determinados elementos histórico-culturales que son apreciados en un determinado contexto nacional pero no necesariamente en otro.

\section{CONCLUSIONES}

La principal crítica que se ha vertido acerca de la doctrina del margen de apreciación nacional, o, más correctamente, sobre el uso que de la misma ha venido haciendo en estas décadas el TEDH ha sido la de la falta de sistematización o concreción de los factores que la integran, en detrimento de la seguridad jurídica. Para un importante número de autores, la construcción que el Tribunal ha hecho de la doctrina, sobre todo, a partir del momento en que la misma no se ciñe ya necesariamente a las situaciones excepcionales pre-

${ }^{57}$ SÁnChez Lorenzo, S., «Derechos fundamentales y libertades de circulación A la sombra de una Constitución para Europa: Comentario a la Sentencia TJCE (Sala $1^{\mathrm{a}}$ ) de 14 de octubre de 2004 (AS. C-36/02: «Omega») », Revista de Derecho Constitucional Europeo, n. ${ }^{\circ}$ 5, enero-junio 2006, p. 387. Se recoge también un comentario de este caso en Gómez SÁnchez, Y., «Dignidad y ordenamiento comunitario», Revista de Derecho Constitucional Europeo, n. ${ }^{\circ}$ 4, julio-diciembre 2005, pp. 237 y 238. 
vistas en el artículo 15 del Convenio, carece de la precisión necesaria que hubiera de permitir a los diferentes actores predecir mínimamente cuándo puede o no acudirse a ella fuera de lo dispuesto por dicho artículo.

Sin embargo, no debemos olvidar que se trata de una doctrina elaborada a golpe de sentencia y que, en cuanto tal, su precisión no puede ser la misma que la que pudiera predicarse de un principio claramente normativizado en el Convenio, más aún, cuando el propio TEDH ha declarado que el Convenio es un instrumento vivo (living constitution).

Por otro lado, nadie podrá negar que el CEDH ha triunfado en el marco europeo e, incluso, más allá del mismo (véase, la Corte Interamericana de Derechos Humanos), y ello, en gran parte creemos que ha venido motivado no sólo por la solidez que ha mostrado la doctrina jurisprudencial del TEDH, sino también porque dicho Tribunal ha sabido apreciar sabiamente las dificultades que, para el buen fin del Convenio, hubiera provocado una aplicación de sus preceptos claramente descontextualizada. Tanto la Comisión como el TEDH han sido conscientes de que la exigencia de garantizar los derechos y libertades de los europeos más allá del concreto marco nacional, que devino inexorable tras la Segunda Guerra Mundial, no podía desatender el hecho de que entre los Estados miembros siguen existiendo diferencias sociales, culturales, políticas y económicas, y más aún cuando ya no hablamos de la algo más de una decena de Estados que iniciaron el proyecto, sino de cuarenta y siete Estados, es decir, ochocientos millones de personas.

Puede compartirse así la opinión de que la doctrina del margen de apreciación nacional permite al TEDH operar no sólo en el marco abstracto de la universalización, sino también mirar más profundamente en el nivel real de aplicación del Convenio ${ }^{58}$. Este equilibrio entre europeización y contextualización no es, en modo alguno, sencillo y, como tal, tampoco puede serlo la construcción de una doctrina que ha de atender a tan vasto marco de diferencias y contextos.

En definitiva, si bien pudiera serle exigible al TEDH avanzar en la creación de un cuerpo dogmático cada vez más claro y preciso acerca de la doctrina del margen de apreciación nacional, de manera que puedan quedar despejadas muchas de las dudas que sigue generando su aplicación en los diferentes casos que caen bajo la jurisdicción del Tribunal, tampoco podemos olvidar que la doctrina habrá de estar necesariamente presidida por cierto casuismo inevitable y que ello obedece no sólo a la diversidad existente en Europa, sino también a que dicha diversidad es también cambiante.

Sobre tal exigencia de claridad debe destacarse el concepto de consenso al que frecuentemente recurre el TEDH en aplicación de la doctrina. Cierto es que el Tribunal realiza, al amparo del mismo, un análisis comparativo de

${ }^{58}$ Ostrowksy, A. A., «What's so funny about peace, love, and understanding? ...», cit., p. 59. 
la situación que determinados límites a los derechos y libertades presenta en el marco interno de regulación de los Estados miembros. Sin embargo, en algunas de las resoluciones en las que se acude a dicho criterio no queda suficientemente claro si dicho consenso exige una regulación uniforme en todos los Estados miembros o, simplemente, en una mayoría relativa de los mismos. Además, el correcto entendimiento del concepto parece haberse complicado a partir de la introducción del nuevo concepto alternativo de la tendencia internacional continuada.

En todo caso, con independencia de que sea oportuno que el TEDH vaya perfilando la doctrina del margen en pos de la seguridad jurídica, desde una perspectiva más general acerca de la universalización (europeización) de los derechos y libertades, habrá que comenzar por distinguir dentro de los derechos humanos el núcleo duro o derechos propiamente fundamentales del resto de los demás derechos humanos. Los primeros habrán de ser universalizados en su formulación actual, en cuanto que traducen directamente las exigencias primordiales de la dignidad de toda persona humana. El resto expresan derechos irrenunciables de las personas y de los pueblos, pero no exigibles con la misma precedencia, y su universalización habrá de realizarse atendiendo a las diferencias histórico-culturales justamente para hacerlos inteligibles y aceptables en todos los países de la tierra.

No puede afirmarse que los derechos humanos constituyan en todas sus vertientes elementos universales que no gozan de particularismos o concreciones en atención a cuestiones morales, culturales, económicas, históricas, etc. Puede admitirse una tendencia positiva hacia la universalización de los derechos humanos junto a la revisión crítica de lo que son propuestas de globalización descontextualizadas o que responden a valores ajenos a la sociedad en la que pretenden proclamarse los derechos.

Y ello no se contradice o impide la pretensión universalizadora de los derechos y libertades. Simplemente, propone soluciones que impidan que la descontextualización provoque, a la postre, un debilitamiento de los derechos. 